\title{
Ethics in Wildlife Rehabilitation
}

ERICA A. Miller, DVM

New Jersey Division of Fish and Wildlife

Office of Fish and Wildlife Health and Forensics

NEW JERSEY

Keywords: Regulations, wildlife, veterinary, permits, Migratory Bird Treaty Act

\section{INTRODUCTION AND BACKGROUND}

The concept of ethics can easily become a very personal matter, and the views presented are those the author has gathered and developed over many years. They are not necessarily the views of the National Wildlife Rehabilitators Association, nor are they meant to be the only acceptable views on ethics, wildlife rehabilitation, or the role of veterinarians in wildlife medicine. It is hoped that the information presented will give the reader some understanding of the Wildlife Rehabilitators Code of Ethics (Miller 2012) and the views presented will inspire each reader to do some thinking about his or her personal views regarding wildlife rehabilitation.

As the topic of ethics in wildlife rehabilitation is examined, it quickly becomes apparent that ethics is a component of decision-making. When a decision must be made, the situation is often a crisis and may be highly emotional. Consequently, responses are often more reflex in nature and do not involve as much conscious thought as they probably should.

All of the decisions that wildlife rehabilitators make are based on a combination of facts and ethics. Facts and ethics can be viewed as the tools in an 'ethical toolbox.' The more rehabilitators can accumulate facts and maintain strong ethics (better tools), the easier it is to use these tools to make good decisions. This paper is not intended to provide answers, but will hopefully provide some 'tools' for the rehabilitator to use in making decisions. This paper also provides some things to consider before facing the various moral dilemmas often encountered in wildlife rehabilitation.

Erica Miller, DVM is a consulting veterinarian with TriState Bird Rescue and Research and the New Jersey Division of Fish and Wildlife, Office of Fish and Wildlife Health and Forensics. She is an adjunct Associate Professor at the University of Pennsylvania School of Veterinary Medicine.

\section{ETHICS}

Dictionaries provide at least three definitions of ethics applicable to wildlife rehabilitation:

1. A system of moral principles (Stein and Su 1978).

2. A principle of right or good conduct, or a body of principles (Morris 1971). Principle means a basic truth, law, or assumption, or a rule or standard, especially of good behavior (Morris 1971).

3. The rules or standards governing the conduct of the members of a profession (Morris 1971).

Bernard Rollin (1999) defined ethics as "the set of principles that governs people's views of right and wrong, good and bad, fair and unfair, just and unjust." Rollin goes on further to break ethics into three categories:

1. Social consensus ethics: those ethical rules believed to be universally binding on all members of society.

2. Personal ethics: ethical behaviors left to the discretion of the individual.

3. Professional ethics: the specialized set of ethics developed to cover the special situations that a profession deals with on a daily basis.

Let's use a simple illustration to explain these concepts. Social consensus ethics in North America says that it is unethical to shoot an eagle. As with many social consensus ethics, the ethic is also a law. An individual's personal ethic may say that it is unethical to shoot any type of bird, or it may say that hunting is acceptable under certain circumstances.

If a gunshot eagle is brought to a wildlife rehabilitator, the rehabilitator has a number of decisions to make, using professional ethics in the process. For veterinarians, the professional toolbox contains the Veterinarian's Oath and the Principles of Veterinary Ethics (AVMA 2001). Veterinarians tend to approach 
their work with the attitude that their job is "to make the animal well and free from pain" (Figure 1). Wildlife rehabilitators have another tool in their ethical toolbox, A Wildlife Rehabilitator's Code of Ethics (Miller 2012). Wildlife rehabilitators approach their work with the attitude that their goal is "to return the animal to viable function in the wild." them. More recently, humans moved from viewing animals as 'beasts of burden' to viewing them as individuals, companions, and even family. Consequently, veterinary ethics experienced the need to grow beyond the mere issue of cruelty to animals.

Even wildlife rehabilitation, which has always been concerned more with individuals than popula-

\section{Being admitted to the profession of veterinary medicine, I solemnly swear to use my scientific knowledge and skills for the benefit of society through the protection of animal health and welfare, the prevention and relief of animal suffering, the conservation of animal resources, the promotion of public health, and the advancement of medical knowledge. \\ I will practice my profession conscientiously, with dignity, and in keeping with the principles of veterinary medical ethics. \\ I accept as a lifelong obligation the continual improvement of my professional knowledge and competence.}

-Adopted by the AVMA 2010-

Figure 1. The Veterinarian's Oath (AVMA 2010).

Rehabilitators and veterinarians have certain obligations that go along with their decision making. These obligations are:

- To the finder of the animal who is entrusting the animal's care to them.

- To their peers. Actions are a reflection on a profession.

- To society. Society has expectations that wildlife rehabilitators will serve society by caring for the animal.

- To themselves. Wildlife rehabilitators and veterinarians have to live with their decisions.

- To the animals. Wildlife rehabilitators and veterinarians are responsible for the welfare of their patients.

Ethics are not static. Ethics change as people grow, learn, and change; as wildlife rehabilitation as a profession changes; and as society changes. Social consensus ethics regarding wildlife changed tremendously in the last 30 to 40 years, resulting largely from a change in human relationships with animals. Less than 100 years ago, it was acceptable to shoot eagles. John James Audubon 'collected' his specimens for making his paintings and subsequent field guides by shooting tions, has become increasingly aware of the welfare of the individual animal. Concern shifted from getting animals functioning again and returning them to the wild, to addressing their individual needs while in captivity. More attention is being given to reducing stress, alleviating pain, increasing comfort, improving nutrition, enriching captive habitat, and enhancing normal behaviors while in captivity. These new approaches are becoming ethical standards.

\section{WILDLIFE REHABILITATION}

Wildlife rehabilitation is the treatment and temporary care of injured, diseased, and displaced indigenous animals, and the subsequent release of healthy animals to appropriate habitats in the wild (Miller 2012). The first decisions anyone makes regarding wildlife rehabilitation are usually, "Should I participate in wildlife rehabilitation, and at what level?" However, many people just 'find' themselves doing rehabilitation without really going through a conscious decision-making process. Perhaps a neighborhood child brought an injured bird to the door and the person felt compelled to help. Soon, other people started bringing nestlings to her and she found herself viewed as 'the bird lady' in her community. Maybe a future rehabilitator found a young squirrel in his yard and raised it. Successful 
or not, this experience may have caused that person to become interested in helping wildlife. Maybe the opportunity to assist with an oil spill response or to watch a release at a local nature center provided more gratification than their everyday jobs, and rehabilitating wildlife became a newfound passion.

However it occurs, when anyone makes the decision to rehabilitate wildlife, they need to look at their personal reasons. Is the wildlife rehabilitator advocating for the animal, for the finder, for the wildlife population, or for their own personal interest? None of these reasons is wrong. Reflecting on the reasons helps a person realize where they are coming from and helps to guide them to where they intend to go.

Wildlife rehabilitation is generally done to help an injured animal. However, through wildlife rehabilitation, individuals can make an impact far beyond that one animal. They can:

- Contribute to wildlife conservation, especially through work with endangered and threatened species or when assisting entire populations, as in oil spill response efforts.

- Gather data and learn about species and procedures. Wildlife rehabilitators were the first to identify certain disease or toxin problems affecting wildlife (Porter 1987).

- Educate each individual who brings an animal for treatment, and educate themselves and volunteers with each case seen.

- Offset human damage. Eighty to 90 percent of the animals brought to wildlife rehabilitators have problems due directly or indirectly to human activity. Through their efforts, many wildlife rehabilitators have a 'chance to give back' (Wood 1985).

\section{CODE OF ETHICS}

A Wildlife Rehabilitator's Code of Ethics was written by founding members of the National Wildlife Rehabilitators Association and the International Wildlife Rehabilitation Council almost 40 years ago (Miller 2000). These ethics changed little during that time and became incorporated into the permit process for wildlife rehabilitation in many states. These ethics and standards were not thrust upon wildlife rehabilitators by the regulatory agencies, but were self-imposed. They were written by and for wildlife rehabilitators.

The code of ethics is wildlife rehabilitators' statement of what they intend to do and how they should do it.
1. A wildlife rehabilitator should strive to achieve high standards of animal care through knowledge and an understanding of the field. Continuing efforts must be made to keep informed of current rehabilitation information, methods, and regulations.

Wildlife rehabilitators need to strive to continually improve their techniques and learn from each other how to best help their wildlife patients.

2. A wildlife rehabilitator should be responsible, conscientious, and dedicated, and should continuously work toward improving the quality of care given to wild animals undergoing rehabilitation.

The author has never met a wildlife rehabilitator who was not dedicated. Unfortunately, she has met rehabilitators who are not always as responsible or conscientious as they should be. When someone takes responsibility for the care of wild animals, it is their obligation to act responsibly and conscientiously. Rehabilitators owe it to both the animal and the person who found the animal.

3. A wildlife rehabilitator must abide by local, state, provincial, and federal laws concerning wildlife, wildlife rehabilitation, and associated activities.

Wildlife rehabilitators must abide by the laws concerning wildlife. Wildlife rehabilitators should read their permits; know the local regulations regarding rabies vector species, white-tailed deer (Odocoileus virginianus), and 'nuisance' wildlife; and know their legal limits. If wildlife rehabilitators do not do this, they reflect poorly on themselves and on their profession, and they demonstrate immediately that they lack ethics or any regard for ethics. Note that this statement also includes the phrase "and associated activities." Wildlife rehabilitators must abide by these local, state, and federal laws while doing anything in conjunction with rehabilitation. This includes seeking donations, conducting any business activities, educating the public, constructing cages or buildings, disposing of animal wastes and carcasses, etc.

4. A wildlife rehabilitator should establish safe work habits and conditions, abiding by current health and safety practices at all times.

This statement is simply good advice. In the case of centers or clinics with paid staff, it is also law (regulated by the Occupational Safety and Health Administration), but for most rehabilitators, it is just good sense. Wildlife rehabilitators should keep their work environments safe-for 
themselves, for their volunteers, and for the animals. Wildlife rehabilitators need to train themselves to think like the animals in their care, anticipate how they might injure themselves in their cages, and make any necessary changes to avoid those injuries. Diseases can be easily spread in captivity-between animals, from animals to humans, and from patients back into wild populations.

5. A wildlife rehabilitator should acknowledge limitations and enlist the assistance of a veterinarian or other trained professional when appropriate.

This item can be tough to follow. Consequently, the author found that she has the greatest amount of respect for those individuals who actually acknowledge their limitations. Many people seem to be afraid to say "I don't know" or to ask for help. However, admitting ignorance and asking for help are the best ways to learn and usually result in the best care for the animals. Wildlife rehabilitation is still a relatively new field and involves many species. Little is known about the appropriate housing and feeding of many species, let alone their various diseases, metabolic pathways, responses to medications, and methods of healing.

Veterinarians do not have all the answers. In fact, when it comes to wildlife, most veterinarians have very few of the answers and should be asking more questions. In regard to medical problems with the animals, veterinarians may have answers or may be able to provide specialized skills. However, do not overlook other trained professionals, including state biologists, zoo nutritionists, pathologists, ornithologists, and naturalists. These individuals may also include anyone with the experience and expertise to help the rehabilitator find the information needed.

Do not overlook one of the most important resources-other wildlife rehabilitators, even though a wildlife rehabilitator may not agree with everything another rehabilitator does. Everyone has things that they do very well, or that work well for certain animals in certain circumstances. Wildlife rehabilitators should ask around, share information, and use personal judgment as to what methods and procedures will work best for a particular situation. State and national organizations provide the means for easy access to networking. Join the National Wildlife Rehabilitators Association and the International Wildlife Rehabilitation Council and, if nothing else, learn to use their membership directories. Asking, searching, and networking are well worth the time and effort, as the end result will be better care for wildlife patients.

6. A wildlife rehabilitator should respect other rehabilitators and persons in related fields, sharing skills and knowledge in the spirit of cooperation for the welfare of the animals.

As stated before, a rehabilitator should share skills and knowledge. This can range from sharing information via a simple phone call or a conversation with one person, via a group chat on the internet, or through printed articles and presentations at the local or national level. Wildlife rehabilitators may not always agree with their colleagues in rehabilitation or related fields, but they should remember to respect others' opinions. Their experiences will be different, and consequently, their perspectives will be different. A wildlife rehabilitator need not abide by them, but just accept them as different.

7. A wildlife rehabilitator should place optimum animal care above personal gain.

Wildlife rehabilitators need to make sure that their egos do not interfere with patient welfare. Balance the knowledge, or even the feeling of success gained in attempting to treat an animal, with the impact the treatment process may have on the animal. It is exciting to receive a rare and seldomtreated species, and it may be desirable to be the one individual who finally succeeds in rehabilitating that species to the point of return to the wild. However, it is a moral obligation to that animal and to the profession to transfer the animal to another's care if the facility or one's medical ability is not suited to the needs of that species and another facility/individual can provide that animal with a better chance of survival.

8. A wildlife rehabilitator should strive to provide professional and humane care in all phases of wildlife rehabilitation, respecting the wildness and maintaining the dignity of each animal in life and in death. Releasable animals should be maintained in a wild condition and released as soon as appropriate. Nonreleasable animals that are inappropriate for education, foster parenting, or captive breeding have the right to euthanasia.

Previous items concluded that wildlife rehabilitators should strive to provide the best care for their wildlife patients. This item takes this concept a step further. It states that wildlife rehabilitators 
should provide care with respect, and maintain the dignity of the animal.

All life-human, animal, or otherwise-deserves respect. The author believes that all animals have some sort of dignity. Remember this throughout the rehabilitation process, and be considerate of the comfort and dignity of the animal while it is in captivity. An animal is not helped if it is habituated to humans or kept in physically and/or psychologically uncomfortable or unhealthy situations. If wildlife rehabilitators cannot ensure that an animal will have a chance at dignity in its life, they can provide it with dignity in its death.

9. A wildlife rehabilitator should encourage community support and public education. The common goal should be to promote a responsible concern for living beings and the welfare of the environment.

Wildlife rehabilitators' work can be farreaching, if time is taken to reach out. Simple ways to share knowledge with the public include individual conversations with clients, talks to school groups, and articles in the newspaper or on websites. Unlimited opportunities exist to teach and influence many people.

10. A wildlife rehabilitator should work on the basis of sound ecological principles, incorporating appropriate conservation ethics and an attitude of stewardship.

Wildlife rehabilitators need to respect the ideas and opinions of their colleagues in wildlife biology. Although wildlife rehabilitators usually focus on the individual, they should remain open to the views of those focusing on wildlife populations. If wildlife rehabilitators are open to understanding the issues and value of population biology, wildlife biologists will be more open to remembering that populations are made up of individuals. Remember that caring for individual animals is only part of wildlife rehabilitation. To truly care for the animal, everyone must also care for their environment.

11. A wildlife rehabilitator should conduct all business and activities in a professional manner-with honesty, integrity, compassion, and commitment-realizing that an individual's conduct reflects on the entire field of wildlife rehabilitation.

Professionals are generally thought to be individuals who either receive pay for their work (e.g., professional athletes) or have an advanced or specialized education in a particular field. Few individuals actually get paid for rehabilitation work, and even fewer have formal training in rehabilitation beyond some workshops or seminars. 'A professional manner' means working and interacting with others with honesty, integrity, compassion, and commitment. If wildlife rehabilitators do these things, they are truly professionals. When wildlife rehabilitators conduct themselves in a professional manner, they can take pride in who they are and what they do, and will gain trust, respect, and credibility that enables them to do even more for wildlife.

\section{CONCLUSION}

To sum up the Wildlife Rehabilitators Code of Ethics, let's take a look at some of the key words and phrases that are used: strive to, responsible, respect and respecting, cooperation, conscientious, and compassion. Not to forget: professional, dignity, quality of care, and welfare of the animals. Caring for injured wildlife is a small part of wildlife rehabilitation.

Rehabilitation also includes the following:

- Returning to the wild: Wildlife rehabilitators return what humans have taken. They do not make pets or cage and confine these wild animals.

- Educating: They educate, either in groups or oneon-one, with the general public, and with other wildlife rehabilitators.

- Learning: Wildlife rehabilitators learn medical procedures, natural history, and husbandry techniques, and they also learn about themselves from each animal they treat. As they go about all aspects of their work (including sharing information, listening to other people's opinions, and encountering new ideas), the author encourages wildlife rehabilitators to keep the code of ethics in mind and not lose sight of the wildlife rehabilitator's mission: the treatment and temporary care of injured, diseased, and displaced indigenous animals and the subsequent release of healthy animals to appropriate habitats in the wild.

\section{ACKNOWLEDGMENT}

The author would like to thank Elaine Thrune for her inspiration and encouragement invested in this topic at both a personal and professional level.

\section{LITERATURE CITED}

AVMA. 2001. Directory and Resource Manual. 50th edition. American Veterinary Medical Association: Schaumburg, IL. 
AVMA. 2010. Veterinarian's Oath. Available from: <https://www.avma.org/KB/Policies/Pages/veterinarians-oath.aspx>.

Miller, E. A., editor. 2000. Minimum Standards for Wildlife Rehabilitation, 3rd edition. National Wildlife Rehabilitators Association: St. Cloud, MN.

Miller, E. A., editor. 2012. Minimum Standards for Wildlife Rehabilitation, 4th edition. National Wildlife Rehabilitators Association: St. Cloud, MN.

Morris, W., editor. 1971. The American Heritage Dictionary of the English Language. American Heritage Publishing Co.: Boston, MA.

Porter, S. L. 1987. Pesticide Use in Virginia. Pp 39-44 in Wildlife Rehabilitation, Vol 6 (D. J. Mackey editor). Coconut Creek Publishing Company: Coconut Creek, FL.
Rollin, B. E. 1999. An Introduction to Veterinary Medical Ethics: Theory and Cases. Iowa State University Press: Ames, IA.

Stein, J., and P. Y. Su, editors. 1978. The Random House Dictionary. Random House: New York, NY. Wood, D. Wild Again (song). Copyright 1985 by Douglas Wood.

\section{RECOMMENDED READING}

Florida State University Psychosocial Stress

Research Program. 1994. Compassion Fatigue

Test from ACE (American Continuing

Education). Available from <http://www. valueoptions.com/providers/Education_Center/ Training_Workshops/Handouts/032106/032106_ Compassion_Fatigue_Test_from_ACE.pdf>.

Joosten, S., and A. Moore, editors. 2004. Principles of Wildlife Rehabilitation, 2nd edition. [Including A Wildlife Rehabilitators Code of Ethics] National Wildlife Rehabilitators Association: St. Cloud, $\mathrm{MN}$. 道是

\section{New NWRA Publication!!}

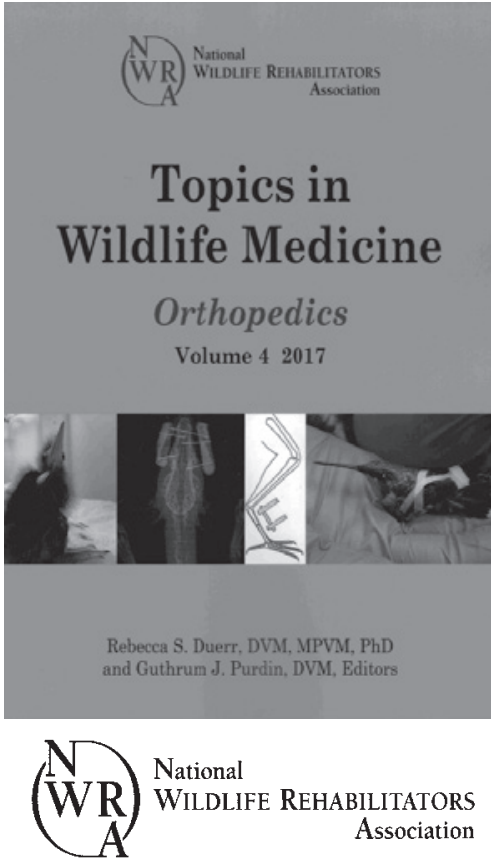

Topics in Wildlife Medicine Volume 4: Orthopedics was created to help veterinarians and wildlife rehabilitators manage fractures in native North American wildlife. From wraps and splints to surgical techniques and ethical considerations for different species, this book covers a lot of ground! The authors of each chapter are veterinarians and experienced wildlife rehabilitators who specialize in wildlife rehabilitation medicine. Both rehabilitators and their veterinarians will benefit from the tips, tricks, and techniques described within.

Topics in Wildlife Medicine Volume 4: Orthopedics is available to Members for $\$ 44.75$ (p\&h included), and Non-members for $\$ 50.75$ (p\&h included). For shipping to Canada or outside the US, please contact us for pricing.

To order your copy of Topics in Wildlife Medicine Volume 4: Orthopedics, please send a check or money order in US Dollars to:

NWRA Sales

2625 Clearwater Rd, Ste 110

St. Cloud, MN 56301
Call (320) 230-9920,

email us at NWRA@NWRAwildlife.org,

or visit us online at www.NWRAwildlife.org. 